\title{
Massive pulmonary hemorrhage from dual circulation pulmonary arteriovenous malformations in hereditary hemorrhagic telangiectasia
}

\author{
Krishna B Sharma MD FRCPC ${ }^{1}$, Lutz Forkert MD FCCP ${ }^{2}$
}

\begin{abstract}
KB Sharma, L Forkert. Massive pulmonary hemorrhage from dual circulation pulmonary arteriovenous malformations in hereditary hemorrhagic telangiectasia. Can Respir J 2004;11(8):597-598.

Pulmonary arteriovenous malformations (AVMs) are commonly supplied by the pulmonary arterial system and rarely by the systemic bronchial circulation. The authors outline the case of a young woman with pulmonary AVMs as part of hereditary hemorrhagic telangiectasia with the uncommon presentation of massive hemoptysis. Management of her recurrent, life-threatening pulmonary hemorrhage was complicated by pulmonary AVMs that were supplied by both the pulmonary and systemic bronchial arterial circulatory systems. Transcatheter embolotherapy of the higher pressure bronchial systemic circuit was necessary for acute hemostasis.
\end{abstract}

Key Words: Arteriovenous malformations; Bronchial arteries; Embolization, therapeutic; Hemoptysis; Pulmonary artery; Telangiectasia, hereditary hemorrhagic

Dulmonary arteriovenous malformations (AVMs) are caused by abnormal communications between pulmonary arteries and pulmonary veins, which bypass the normal capillary bed and cause a low resistance right-to-left shunt. Pulmonary AVMs are supplied by the pulmonary arterial system in approximately $95 \%$ of cases; the systemic (bronchial) arteries contribute much less frequently (1). Supply from systemic arteries other than bronchial arteries has been described, such as from the internal mammary artery (2). Pulmonary or bronchial AVMs are supplied by a single feeding artery and a single draining vein ('simple' type). Only $10 \%$ to $20 \%$ of AVMs are complex, with two or more feeding arteries or draining veins (1). The large majority of AVMs are supplied from a single circulation, either pulmonary or systemic.

The dilated thin walls of pulmonary AVMs can spontaneously rupture, leading to hemoptysis or hemothorax. Massive, life-threatening pulmonary hemorrhage due to pulmonary AVMs has been documented in case reports and series; however, it is an unusual initial presentation (3).

\section{CASE PRESENTATION}

The patient was a 20-year-old Canadian-born Asian woman whose past medical history was significant only for

\section{Hémorragie pulmonaire massive des suites d'une double malformation artérioveineuse pulmonaire en présence de télangiectasie hémorragique héréditaire}

\begin{abstract}
Les malformations artérioveineuses pulmonaires (MAVP) sont souvent alimentées par le système artériel pulmonaire et rarement par la circulation bronchique systémique. Les auteurs décrivent le cas d'une jeune femme atteinte de MAVP avec, en arrière-plan, télangiectasie hémorragique héréditaire et tableau inusité d'hémoptysie massive. La prise en charge de son hémorragie pulmonaire gravissime récurrente a été compliquée par la présence de MAVP alimentées à la fois par la circulation pulmonaire et par le réseau artériel bronchique systémique. Un traitement de l'embolie par cathéter au niveau du réseau systémique bronchique, soumis à une plus forte pression, s'est révélé nécessaire pour enrayer rapidement l'hémorragie.
\end{abstract}

hypothyroidism, which was well-controlled with levothyroxine and occasional epistaxis. This epistaxis had occurred approximately every two weeks for five years, generally at night. She was a lifelong nonsmoker and denied having taken any drugs.

The patient presented with $500 \mathrm{~mL}$ of bright red hemoptysis. There were no other bleeding sites (including hematemesis and melena), rashes or arthralgia. She had no preceding infection or trauma. The patient was hemodynamically stable and hypoxemic $\left(\mathrm{PO}_{2} 68 \mathrm{mmHg}\right.$ on $\left.4 \mathrm{~L} / \mathrm{min} \mathrm{O}_{2}\right)$. There were no extracardiac murmurs or clubbing. She did not have any mucocutaneous telangiectasias visible on initial physical examination. Her chest radiograph was normal. After a further $300 \mathrm{~mL}$ of witnessed, bright red hemoptysis, she underwent urgent bronchoscopy, which revealed telangiectasias in the posterior pharynx, as well as fresh blood and large clots in the right bronchus intermedius. The patient was intubated; however, there was continued bleeding. A double-lumen endotracheal tube was placed to block the right main bronchus.

The placement of the endotracheal tube provided only temporary relief. Subsequent deflation of the bronchial blocker revealed active bleeding from the right lower lobe orifice.

\footnotetext{
${ }^{1}$ Division of Respirology, Department of Medicine, University of Ottawa, Ottawa; ${ }^{2}$ Division of Respiratory and Critical Care Medicine,

Department of Medicine, Queen's University, Kingston, Ontario

The work was performed at the Kingston General Hospital, Kingston, Ontario

Correspondence: Dr Krishna B Sharma, Carling Respiratory Services, 412-1095 Carling Avenue, Ottawa, Ontario K1Y 4P6.

Telephone 613-729-8262, fax 613-729-7870, e-mail sharma@medscape.com
} 


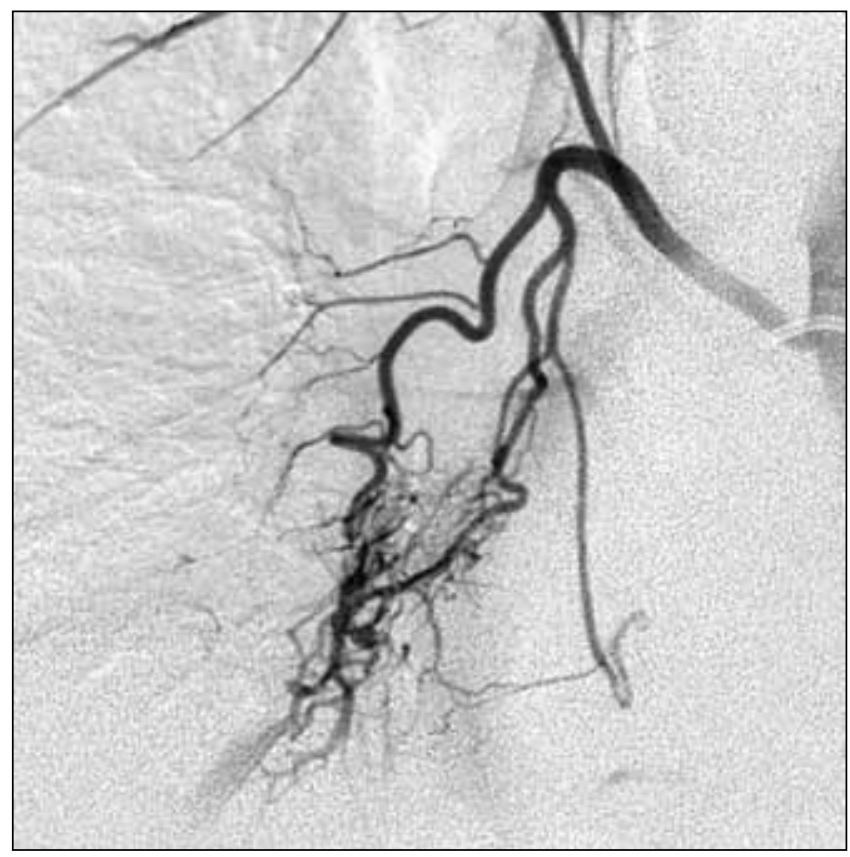

Figure 1) Right-sided bronchial artery systemic angiogram showing arteriovenous malformations (centre) and retrograde blush of contrast dye from pulmonary circulation (lower left)

Bronchial and pulmonary angiography showed an enlarged right bronchial artery trunk with branches to arteriovenous malformations around the right bronchus intermedius. Of greater concern was an unexpected dual blood supply to the AVMs from the pulmonary and bronchial arterial circulation (Figure 1). Hemoglobin had dropped to $62 \mathrm{~g} / \mathrm{L}$ from the admission level of $112 \mathrm{~g} / \mathrm{L}$. Despite having this dual blood supply, the decision was made to embolize the high pressure systemic component with coils via the right bronchial artery.

The patient's subsequent course was characterized by recurrent pulmonary hemorrhage that was controlled by instillation of iced saline and adrenaline into the right lower lobe. However, repeat bronchial and pulmonary angiography showed no contrast extravasation. Given the patient's hemodynamic stability, tamponade of the affected segment of the right lower lobe with an endobronchial balloon-tip catheter was performed rather than lobectomy. The bleeding subsided and the patient was successfully extubated.

A definitive clinical diagnosis of hereditary hemorrhagic telangiectasia (HTT) was made according to the patient's history of epistaxis, oropharyngeal telangiectasias, pulmonary AVMs and family history (the patient's younger brother met the criteria on screening) (4).

\section{DISCUSSION}

Dual blood supply of pulmonary AVMs from both the systemic and pulmonary circulation is very rare. A review of the literature revealed only a few case reports, one of which was complicated by recurrent hemorrhage (5).

The acute management of massive pulmonary hemorrhage secondary to pulmonary AVMs involves stabilization, localization of lesions with angiography and definitive treatment through embolotherapy or surgery (6). Transcatheter embolotherapy involves selective catheterization of the AVM's feeding artery. Steel coils are advanced through the catheter until blood flow to the AVM has stopped. Surgical resection ranging from local excision to pneumonectomy may be required if hemostasis is not achieved through embolization therapy.

When faced with massive hemorrhage, the authors decided to embolize the bronchial circulation instead of the lower pressure pulmonary system. It was hypothesized that there was a greater chance of hemorrhage control with obliteration of the higher pressure circuit (5). Although hemoptysis recurred after embolization, it was of lower magnitude. Contrast extravasation was not demonstrated on follow-up angiography and, ultimately, hemostasis was accomplished without resorting to surgical resection.

\section{CONCLUSIONS}

Pulmonary AVMs are an uncommon cause of hemoptysis; however, they should be considered in previously well, young nonsmoking patients. The majority of pulmonary AVMs with no clear underlying cause are related to HHT. AVMs are generally supplied solely by the pulmonary circulation.

The present case highlights the unusual initial presentation of HHT syndrome with massive, life-threatening hemoptysis. Management of the recurrent pulmonary hemorrhage was complicated by rare dual circulation (both systemic bronchial and pulmonary systems) feeding of the AVMs. Transcatheter embolotherapy of the higher pressure systemic bronchial system was necessary to acutely attain hemostasis.

\section{REFERENCES}

1. Gossage JR, Kanj G. Pulmonary arteriovenous malformations. A state of the art review. Am J Respir Crit Care Med 1998;158:643-61.

2. Thung KH, Sihoe AD, Wan IY, Lee TW, Wong R, Yim AP. Hemoptysis from an unusual pulmonary arteriovenous malformation. Ann Thorac Surg 2003;76:1730-3.

3. Ference BA, Shannon TM, White RI Jr, Zawin M, Burdge CM. Life-threatening pulmonary hemorrhage with pulmonary arteriovenous malformations and hereditary hemorrhagic telangiectasia. Chest 1994;106:1387-90.

4. Shovlin CL, Guttmacher AE, Buscarini E, et al. Diagnostic criteria for hereditary hemorrhagic telangiectasia (Rendu-Osler-Weber syndrome). Am J Med Genet 2000;91:66-7.

5. Wispelaere JF, Trigaux JP, Weynants P, Delos M, Coene BD. Systemic supply to a pulmonary arteriovenous malformation: Potential explanation for recurrence. Cardiovasc Intervent Radiol 1996;19:285-7.

6. Dutton JA, Jackson JE, Hughes JM, et al. Pulmonary arteriovenous malformations: Results of treatment with coil embolization in 53 patients. Am J Roentgenol 1995;165:1119-25. 


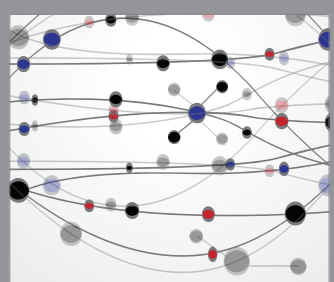

The Scientific World Journal
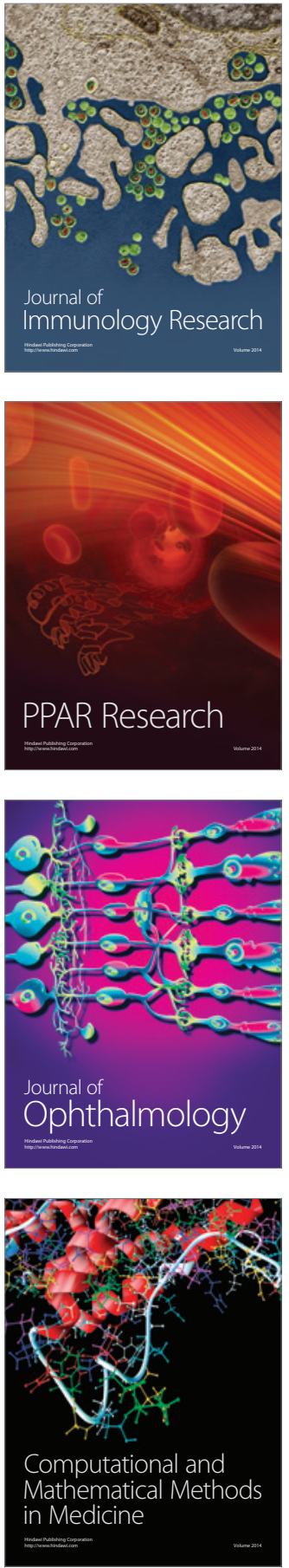

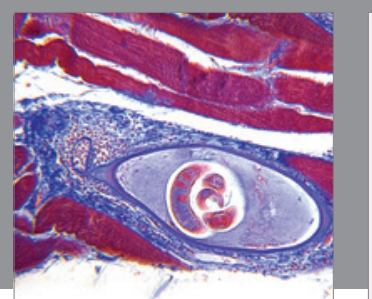

Gastroenterology Research and Practice

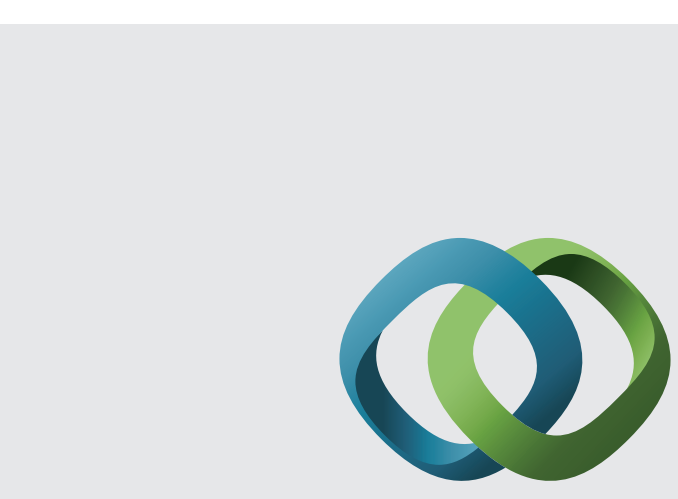

\section{Hindawi}

Submit your manuscripts at

http://www.hindawi.com
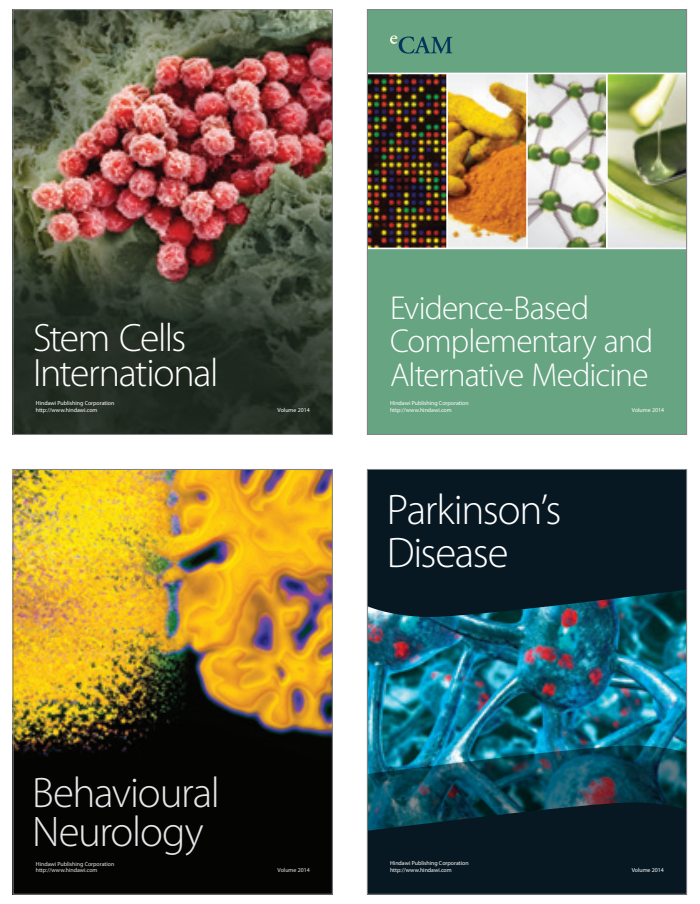
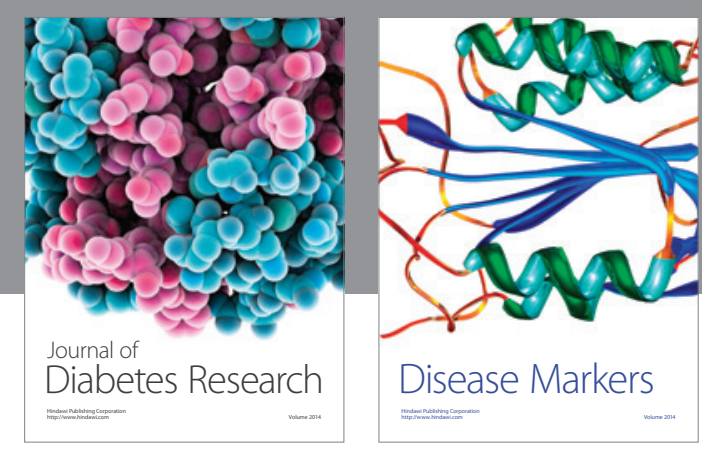

Disease Markers
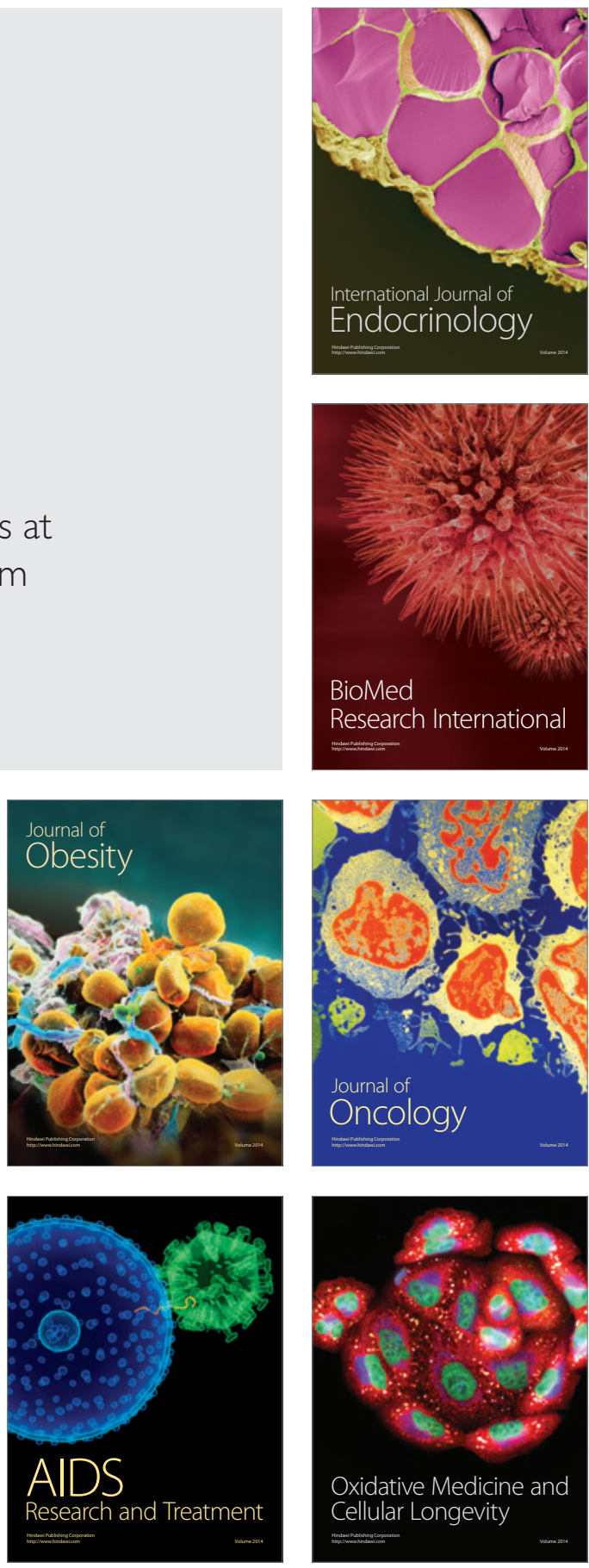